\title{
Primary Immune Deficiency Treatment Consortium
}

National Cancer Institute

\section{Source}

National Cancer Institute. Primary Immune Deficiency Treatment Consortium. NCI

Thesaurus. Code C153199.

A consortium of 42 centers in North America whose shared goal is to improve the outcome of patients with rare, life threatening, inherited disorders of the immune system. 